ARTICLE

DOI: $10.1038 / \mathrm{s} 41467-018-06233-\mathrm{x}$

\title{
Multi-terrane structure controls the contrasting lithospheric evolution beneath the western and central-eastern Tibetan plateau
}

\author{
Pengpeng Huangfu (10) 1, Zhong-Hai Li (10 1,2, Taras Gerya ${ }^{3}$, Weiming Fan ${ }^{1,4,5}$, Kai-Jun Zhang ${ }^{1}$, \\ Huai Zhang ${ }^{1} \&$ Yaolin Shi
}

The Tibetan plateau is manifested by contrasting along-strike lithospheric structures, but its formation mechanism and the relationship with the heterogeneous multi-terrane configuration is a challenging problem. Here we conduct systematic numerical modeling to explore the roles of width, density, and rheological properties of the multiple terranes in the lithospheric evolution of the Tibetan plateau, which reveals two distinct collision modes. In Mode-l, the lithospheric mantles of both the strong and weak terranes in the Tibetan plate are completely detached, followed by the underthrusting of Indian lithosphere beneath the whole plateau. Alternatively, Mode-II is characterized by full detachment of the weak terranes, but (partial) residue of the strong terranes during collision. These two contrasting modes, broadly consistent with the lithospheric structures of western and central-eastern Tibetan plateau, respectively, are strongly dependent on the along-strike variation of the width of the strong Lhasa-Qiangtang terranes.

\footnotetext{
${ }^{1}$ Key Laboratory of Computational Geodynamics, College of Earth and Planetary Sciences, University of Chinese Academy of Sciences, 100049 Beijing, China. ${ }^{2}$ Laboratory for Marine Geology, Qingdao National Laboratory for Marine Science and Technology, 266237 Qingdao, China. ${ }^{3}$ Department of Earth Sciences, Institute of Geophysics, ETH-Zurich, 8092 Zurich, Switzerland. ${ }^{4}$ CAS Center for Excellence in Tibetan Plateau Earth Sciences, 100101 Beijing, China. ${ }^{5}$ Key Laboratory of Continental Collision and Plateau Uplift, Institute of Tibetan Plateau Research, Chinese Academy of Sciences, 100101 Beijing, China.

Correspondence and requests for materials should be addressed to Z.-H.L. (email: li.zhonghai@ucas.ac.cn)
} 
$\mathrm{M}$ any orogenic systems are constructed of multiple allochthonous terranes with distinct evolution histories and geometric-thermo-rheological properties ${ }^{1-4}$. The original heterogeneities of the accreted terranes could significantly affect post-collisional deformation behaviors and overall crustal-lithospheric structure of the collision zone. Taking the Himalayan-Tibetan orogen as an example, the Tibetan lithosphere was composed of accreted terranes before the Cenozoic India-Asia collision ${ }^{3}$ (Fig. 1). The major terranes, from south to north, include Lhasa, Qiangtang, Songpan-Ganzi (SPGZ henceforth), Kunlun-Qaidam, and Qilian terranes. In addition, the Tibetan plateau is also manifested by contrasting along-strike lithospheric structures from west to east ${ }^{5-8}$. Specifically, Indian lithosphere is supposed to horizontally underthrust the western Tibetan plateau ${ }^{5}$, which is presumably accompanied by southward Asian subduction in the Pamir region ${ }^{9-11}$. However, in central-eastern Tibet, the Indian and North China lithospheres separately underthrust southern and northeastern Tibet, with a weak lithospheric region in between, mainly beneath the Qiangtang and SPGZ terranes. This weak lithosphere is marked by high temperature, poor Sn propagation, low Pn velocities, and strikingly large seismic anisotropy ${ }^{5,12-14}$ (Fig. 1). The mechanism of the contrasting lithospheric structures from western to eastern Tibet and the correlation with multi-terrane configuration remain challenging.

The along-strike (west-east) rheological heterogeneities of the Tibetan lithosphere, inherited from its tectonic history, are generally invoked to account for the heterogeneous deep structure beneath the plateau ${ }^{8,15}$. However, it is generally neglected for the across-strike (north-south) variations of the crustal composition and rheological properties among the multiple terranes, which are generally observed ${ }^{3,16}$ and show contrasting characteristics between the terranes south and north of the Jinsha suture, according to the stratigraphy ${ }^{16}$ and pre-Cenozoic tectonic histories ${ }^{3,17,18}$. In addition, the present Tibetan plateau displays an eastward-broadening shape, which might reflect the potential geometry of the Tibetan lithosphere at the onset of the India-Asia collision. Given the above-mentioned along-strike and acrossstrike heterogeneities, it is thus interesting to explore whether and how the intrinsically heterogeneous multi-terrane configuration of the Tibetan lithosphere contributes to the along-strike variations of the lithospheric structure beneath the plateau. The answer to this question is crucial to better understand the dynamics of the India-Asia collision, as well as the development of the Tibetan plateau.

Previous studies revealed that the properties of accreted terranes and the sutures among them can strongly affect the evolution of continental orogens, such as the first-order tectonic structure $^{19}$, crustal/lithospheric deformation behavior ${ }^{20}$, and spatial-temporal patterns of magmatism ${ }^{19,21,22}$. Numerical models, together with geological and geophysical observations, can test the hypotheses for the tectonic evolution of the Tibetan plateau, including distributed crustal shortening and thickening $^{23}$, lateral extrusions along major strike-slip faults ${ }^{24}$, Indian lithosphere underthrusting ${ }^{25}$, and crustal channel flow ${ }^{26,27}$. Most previous numerical studies regarding allochthonous terranes focused on the terrane accretion processes ${ }^{28-30}$, rather than the terminal continental collision and mountain building ${ }^{25,31}$. For the latter cases, Kelly et al. ${ }^{25}$ integrated one soft accreted (Lhasa) terrane in the models, focusing on the roles of the soft Lhasa terrane in tectonic evolution of southern Tibet. Li et al. ${ }^{31}$ conducted similar models, although the weak terrane, sandwiched between the relatively strong Indian and Asian plates, was interpreted as the whole Tibetan lithosphere, rather than only the Lhasa terrane in Kelly et $\mathrm{al}^{25}$. Both independent studies obtained similar conclusions, highlighting the prerequisite of a relatively dense and weak accreted terrane for further delamination/ detachment during convergence, which may be followed by the sub-horizontal underthrusting of Indian lithosphere (see Supplementary Note 1 for details). In all other previous numerical studies, the Tibetan lithosphere was generally simplified to a homogeneous continental plate without considering the abovementioned, significant multi-terrane heterogeneity, thus neglecting the reactivation of pre-existing sutures and its effects on the Indian-Asian collision.

In this study, we perform systematic numerical experiments to explore the effects of different geometric-mechanical properties of multiple terranes on the post-collisional lithospheric deformation, which provides crucial implications for the role of multiterrane configuration in forming the contrasting along-strike lithospheric structures of the Tibetan plateau. The model results are further constrained by post-collisional magmatism and deep mantle tomography, which indicate that the width of relatively stronger Lhasa-Qiangtang terranes is a key controlling factor for the geodynamic evolution of the Tibetan plateau.

\section{Results}

Model setup. We performed two-dimensional (2D) thermomechanical numerical experiments (see Methods) to investigate the correlation of post-collisional crustal-lithospheric structure with the across-strike multi-terrane configuration in collision zones. With respect to the Tibetan plateau, we divided all the terranes constituting the plateau into two composite terranes bordered by the Jinsha suture, according to the stratigraphy ${ }^{16}$ and pre-Cenozoic tectonic histories $3,17,18$. Specifically, the Lhasa and Qiangtang terranes can be regarded as an integrated strong terrane, since both terranes are underlain by the Precambrian crystalline basement that was overlapped by PanAfrican metamorphism and magmatism and then covered by similar Paleozoic marine strata ${ }^{16,32}$. It is generally believed that these two terranes were part of the northern Gondwana margin during most of the Paleozoic ${ }^{17}$, and separated in the Permian $^{3,33}$ or the early Mosozoic ${ }^{17,34}$. However, the terranes north of the Jinsha suture, including the SPGZ, Kunlun-Qaidam, and Qilian terranes, are distinct from the Lhasa and Qiangtang terranes during Paleozoic-Mesozoic times in terms of faunal affinities ${ }^{33}$, detrital zircon ages ${ }^{17}$, and tectonic evolution ${ }^{18}$. Multiple sutures exist in this region $^{18,35-37}$, which indicates that the northern Tibet was a locus of long-lived oceanic subduction and repeated microcontinent/arc-micro-continent collision, followed by orogen collapse-induced rifting or even oceanic spreading since the Neoproterozoic ${ }^{18}$. In combination with the widespread, thick flysch sediments deposited in the SPGZ terrane ${ }^{3}$, intense Cenozoic deformation ${ }^{38}$, and the widely distributed nature of active thrusts in northeastern Tibet ${ }^{20}$, these terranes north of the Jinsha suture are generally considered to be weaker than the southern terranes. Therefore, as a first-order assumption, we integrate the Lhasa and Qiangtang terranes as a composite strong terrane, and all the terranes north of the Jinsha suture as a composite weak terrane in the numerical models (Fig. 2a), in order to reveal the effects of the multi-terrane heterogeneity. Although the two-integrated-terrane configuration is a simplified tectonic structure, it reflects the most fundamental rheological characteristics of the accreted terranes in the Tibetan lithosphere.

A $500-\mathrm{km}$ Neo-Tethyan oceanic lithosphere is also included in the initial model (Fig. 2a), which, together with the two integrated continental terranes, is located between the pro-plate (i.e., Indian plate) and retro-plate (i.e., Tarim-North China plate) (Fig. 2a). Three types of lithospheric rheological profiles are designed for 


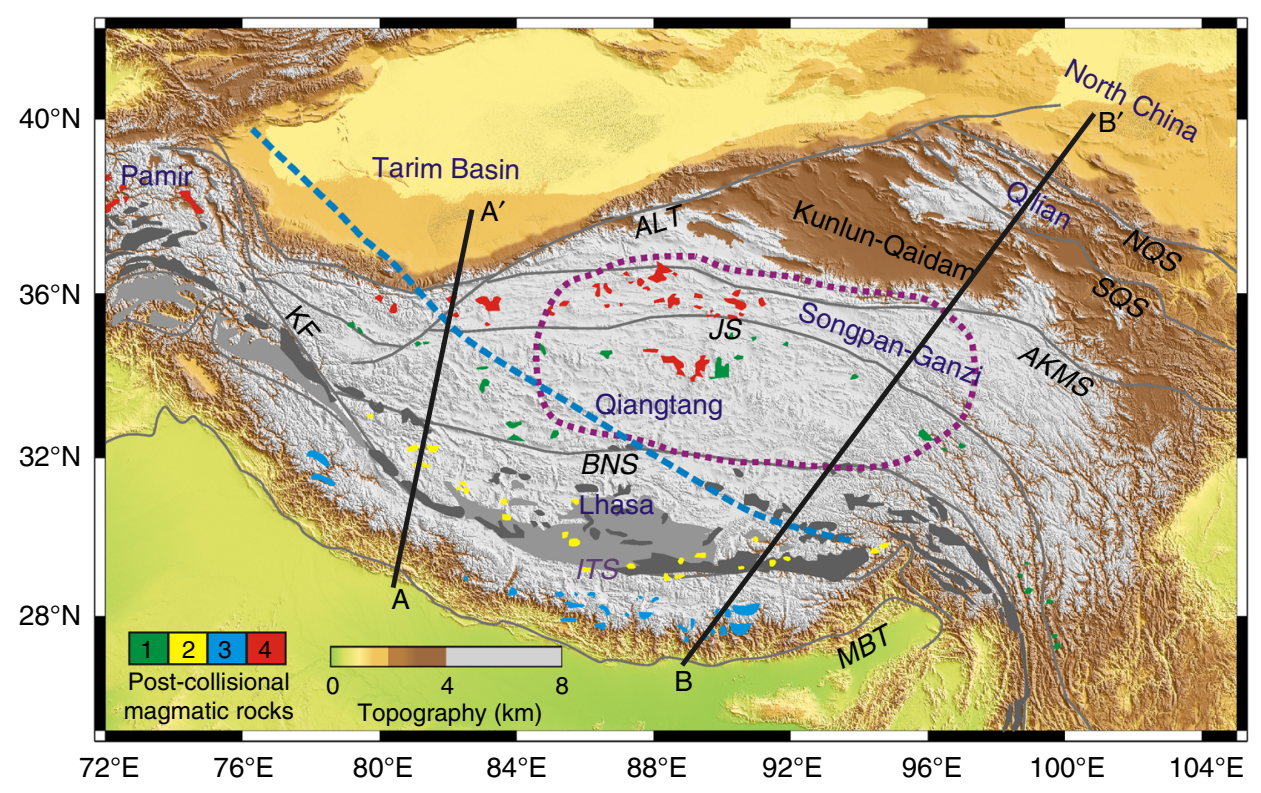

$92^{\circ} \mathrm{E}$

Fig. 1 Tectonic framework of the Tibetan plateau. Four main suites of post-collisional magmatic rocks are shown with different color: 1 (green) = Eocene to Oligocene potassic rocks; 2 (yellow) = Late Oligocene to Mid-Miocene rocks; 3 (blue) = Himalayan leucogranites; 4 (red) = Mid-Miocene to Quaternary potassic rocks $21,49,65$ The dark and light gray areas in southern Tibet denote Gangdese granitoids and Paleogene Linzizong volcanic rocks, respectively 49 . The thick purple dashed line delineates the zone of poor Sn propagation ${ }^{5,12-14}$. The thick blue dashed line represents the northern boundary of the Indian lithosphere at $200 \mathrm{~km}$ depth ${ }^{5}$. Profiles $\mathrm{AA}^{\prime}$ and $\mathrm{BB}^{\prime}$ are locations of schematic cross-sections illustrated in Fig. 6, representing the lithospheric structure of the western and central-eastern Himalayan-Tibetan orogen. Gray lines mark the major fault traces and suture zones. MBT Main Boundary Thrust, ITS Indus-Tsangpo suture, BNS Bangong-Nujiang suture, JS Jinsha suture, AKMS Anyimaqen-Kunlun-Muztagh suture, SQS South Qilian suture, NQS North Qilian suture, KF Karakoram fault, ALT Altyn Tagh fault. The Generic Mapping Tools ${ }^{66}$ was used to create the topographic map, with the topography data from ETOPO1 Global Relief Model (https://www.ngdc.noaa.gov/mgg/global/global.html). In addition, the software CorelDRAW was further used to draw all the other elements in the figure

the pro-/retro-plate, the strong terrane, and the weak terrane (Fig. 2b). Detailed properties of different rock types are described in the Supplementary Tables $1,2$.

In this study, a series of numerical models are constructed with variable width of the strong and weak terranes, as well as variable reference density of their lithospheric mantles. The width of the weak terrane ranges from 400 to $700 \mathrm{~km}$, whereas the strong terrane from 600 to $1200 \mathrm{~km}$. According to the secular evolution from depleted Mg-rich low-density Archean mantle to more fertile, denser Phanerozoic mantle ${ }^{39}$, the reference density (i.e., at the same pressure and temperature) of the depleted pro-plate and retro-plate lithospheric mantle is assigned to be $-30 \mathrm{~kg} \mathrm{~m}^{-3}$ lower than that of the asthenosphere. However, the reference density of the accreted terranes' lithospheric mantle is assumed to be equal to the asthenosphere in the reference models. We also built two other sets of models with slightly higher $\left(+10 \mathrm{~kg} \mathrm{~m}^{-3}\right)$ or lower $\left(-10 \mathrm{~kg} \mathrm{~m}^{-3}\right)$ reference density of the accreted terranes, in order to study the effects of lithospheric density on the deformation behaviors of the terranes during collision.

Two end-member modes controlled by the strong terrane width. According to the deformation behaviors of the accreted terranes, the model results with neutral reference density between the terrane lithospheric mantle and the asthenosphere can be summarized into two contrasting modes as shown in Figs. 3, 4. Mode-I is characterized by complete detachment of the lithospheric mantle of both the strong and weak terranes, thus termed as "complete terrane detachment" mode. In Mode-II, the lithospheric mantle of the weak terrane is fully detached; however, that of the strong terrane is (partially) preserved in the collision zone, which is thus defined as "partial terrane detachment" mode.
Mode-I is marked by "complete terrane detachment" (Fig. 3). In the stage of oceanic subduction, only the leading end of the upper plate close to the suture is slightly deformed in the compressional regime, and the deformation of the whole overriding terranes is negligible (Fig. 3a). When continental collision begins, continuous convergence between the pro-plate and retro-plate is firstly accommodated by the localized deformation in the overriding weak terrane. Consequently, the crust of the weak terrane is scraped off and accreted onto the neighboring strong terrane and retro-plate, whereas the lithospheric mantle is detached and sinks into the asthenosphere (Fig. 3b). Afterwards, the shortening of the strong terrane takes place, with its lithospheric mantle detached following that of the weak terrane, resulting in complete lithospheric detachment of both terranes (Fig. 3c, d). Finally, the advancing pro-plate subhorizontally underthrusts and meets the retro-plate beneath the thickened crust of the detached terranes (Fig. 3e).

Mode-II is characterized by "partial terrane detachment" (Fig. 4). After oceanic subduction (Fig. 4a), the weak terrane begins to subduct beneath the strong terrane in response to the far-field effect of continental collision, which further leads to the detachment of its lithospheric mantle (Fig. 4b, c). Subsequently, the pro-plate and retro-plate subduct beneath the residual strong terrane with opposite directions, forming a double-sided continental subduction scenario (Fig. 4c, d). It is worth noting that the retro-plate subduction is limited, comparing to that of the pro-plate, which is consistent with the geophysical observations ${ }^{40}$. During these processes, the intense upwelling occurs in the confined region beneath the residue strong terrane, with bottom erosion and rheological weakening of the overriding lithosphere. Continued convergence causes further subduction of 

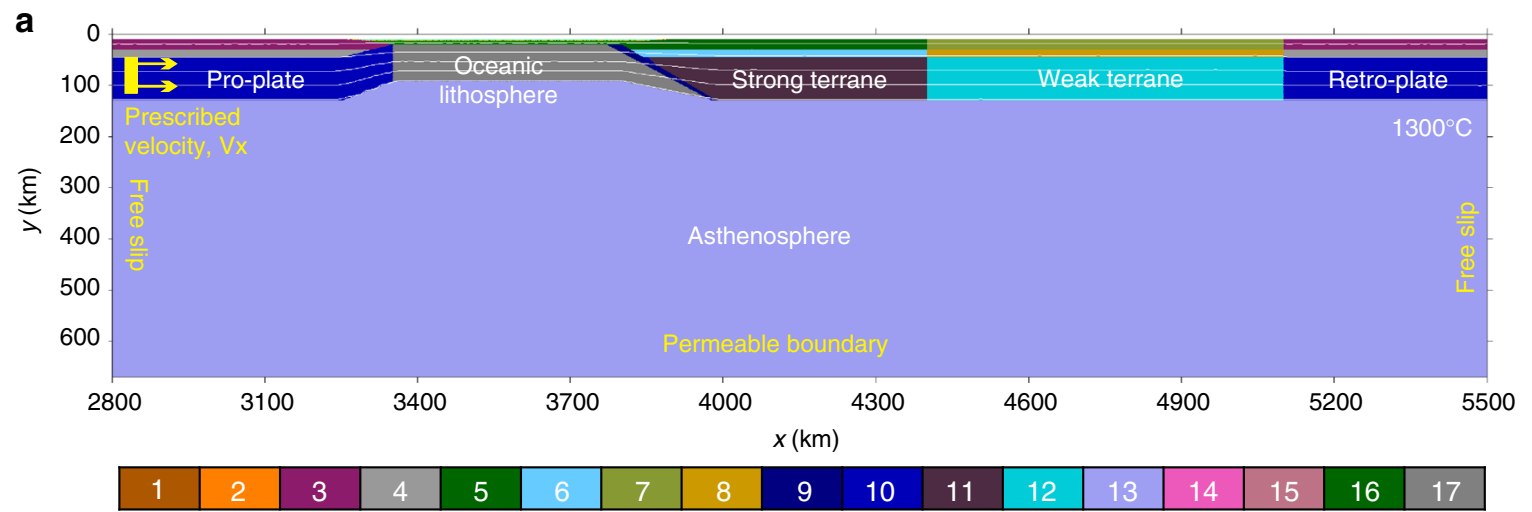

b
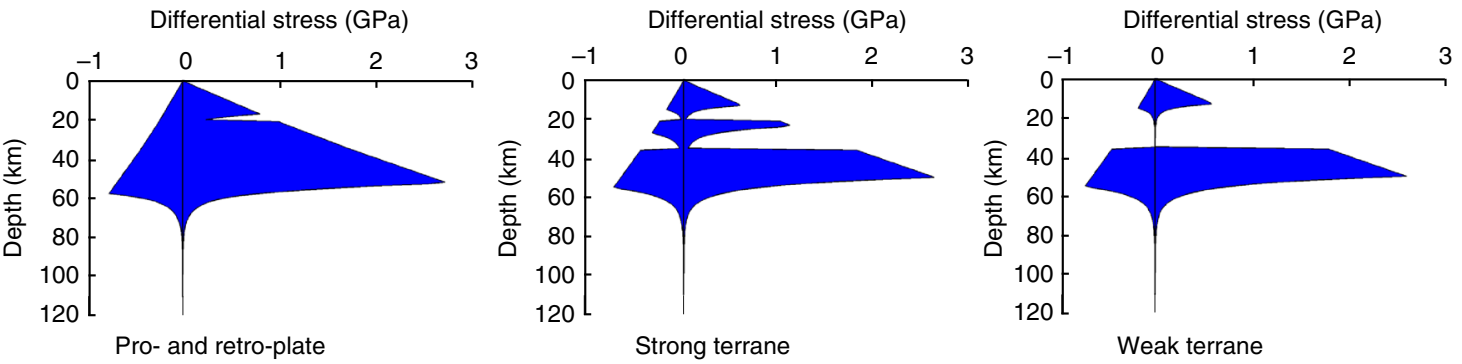

Fig. 2 Model setup. a Initial model configuration. Enlargement $(2700 \times 670 \mathrm{~km})$ of the numerical box $(6400 \times 670 \mathrm{~km})$ is shown. White lines are isotherms with an interval of $300^{\circ} \mathrm{C}$. A constant velocity of $5 \mathrm{~cm} \mathrm{yr}^{-1}$ is assigned within the pro-plate. Different colors refer to different lithologies, with the colorbar: $1 / 2=$ sediment; $3=$ pro-/retro-plate upper crust; $4=$ pro-/retro-plate lower crust; $5=$ strong terrane upper crust; $6=$ strong terrane lower crust; $7=$ weak terrane upper crust; $8=$ weak terrane lower crust; $9=$ initial weak zone; $10=$ pro-lithospheric and retro-lithospheric mantle; $11=$ strong terrane lithospheric mantle; $12=$ weak terrane lithospheric mantle; $13=$ asthenosphere; $14=$ partially molten upper crust of the pro-plate and retro-plate; $15=$ partially molten upper crust of the strong and weak terranes; $16=$ oceanic crust; $17=$ oceanic lithospheric mantle. $\mathbf{b}$ Three rheological structures of the continental lithosphere. Rheological strength profiles are obtained for the 120 - $\mathrm{km}$-thick lithosphere with an initial Moho temperature of $400{ }^{\circ} \mathrm{C}$ for proplate and retro-plate and of $450{ }^{\circ} \mathrm{C}$ for the strong and weak terranes. The prescribed constant strain rate is $10^{-16} \mathrm{~s}^{-1}$

both the pro-plate and retro-plate, shortening deformation of the residue terrane, and significant crustal thickening with intense partial melting in the middle crust (Fig. 4d).

The model results reveal that the contrasting modes are mainly dependent on the width of the strong terrane, whereas that of the weak terrane does not change the general model predictions (Fig. 5c). Specifically, if the strong terrane is narrow $(\leq 800 \mathrm{~km})$, complete detachment of both the weak and strong terranes is predicted. However, the strong terrane cannot be fully detached, when it becomes wider $(\geq 1000 \mathrm{~km})$. From the mechanical perspective, the contrasting modes are mainly attributed to the degree of far-field collision effect on the weak terrane. When the strong terrane is narrow, the compressional stress due to the collision can be readily transferred to retro-side (right side) of the weak terrane, which thus enables the subduction of the weak terrane beneath the retro-plate. This leads to the subsequent subduction of the strong terrane, eventually resulting in the complete detachment of both terranes. However, a relatively wider strong terrane considerably decreases the far-field effect of the collision on the weak terrane. In this case, the deformation tends to localize in the pro-side (left side) of the weak terrane, rather than the retro-side. Thereby, it appears easier for the weak terrane to subduct leftward beneath the strong terrane rather than rightward beneath the retro-plate. In this case, the subduction and detachment of strong terrane is prohibited.

Dependence on the density of terrane lithospheric mantle. The lithospheric density is another critical factor that may control the patterns of lithosphere detachment in collisional orogens, which is further tested with both lower and higher densities. If the reference density of lithospheric mantle of both the strong and weak terranes is decreased to be $-10 \mathrm{~kg} \mathrm{~m}^{-3}$ lower than the asthenosphere, Mode-I with complete detachment of both terranes is only predicted in the models with a narrower strong terrane of $600 \mathrm{~km}$ (Fig. 5d). Alternatively, if the reference density of lithospheric mantle of both the strong and weak terranes is increased to be $+10 \mathrm{~kg} \mathrm{~m}^{-3}$ higher than the asthenosphere, Mode-I with complete terrane detachment develops more extensively in the models with a larger range of strong terrane width $(\leq 1000 \mathrm{~km})$ (Fig. 5e). It indicates that the lithospheric density also strongly affects the detachment modes of the accreted terranes. A larger positive density contrast between the terrane and asthenosphere promotes the detachment during collision, and vice versa.

\section{Discussion}

Various geophysical observations suggest contrasting lithospheric structures beneath the Tibetan plateau ${ }^{5-7,41}$. On the basis of these previous studies, we assemble two distinct schematic interpretations of the present-day lithospheric structural configuration, representing the western and central-eastern Tibetan plateau (Fig. 6). Previous geophysical studies of the entire Himalayan-Tibetan collision zone show systematic along-strike variations of the architecture of the Indian underthrusting 5,6,8,41. Firstly, the horizontal distance over which the Indian lithosphere underthrusts the plateau decreases from west to east. The Indian lithosphere underlies the entire plateau in western Tibet, whereas it roughly reaches the Bangong-Nujiang suture in central Tibet, or subducts steeply around the Indus-Tsangpo suture in eastern Tibet $^{6,42}$. Secondly, the dip angle of the leading end of the subducting Indian slab decreases from east to west $^{8}$. In eastern-central Tibet, the leading edge of the Indian lithosphere 

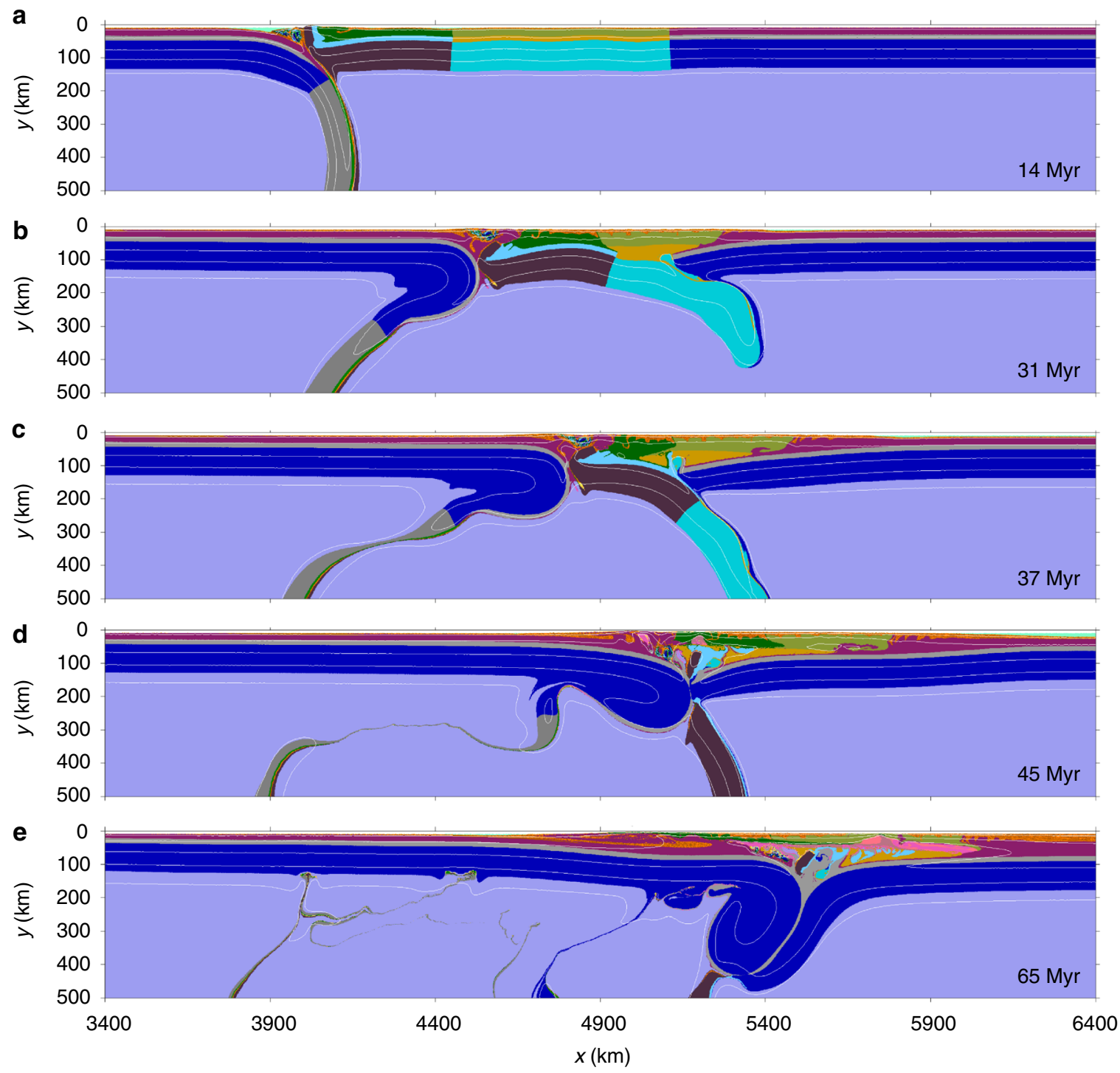

Fig. 3 Evolution of complete terrane detachment mode (Mode-I). The widths of the strong and weak terranes are 600 and 700 km, respectively. The

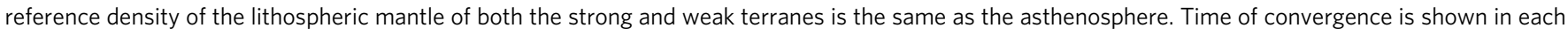
panel. Colors of rock types are as in Fig. 2a. White numbered lines are isotherms plotted every $300^{\circ} \mathrm{C}$ starting from $100^{\circ} \mathrm{C}$

steeply plunges into the mantle beneath the plateau, but in western Tibet, the Indian lithosphere is suggested to horizontally underthrust the plateau without significant sinking. Similar features are also captured in the two contrasting modes as shown in Fig. 5a, b, which reveal their strong dependence on the lithospheric deformation/detachment of the overriding Lhasa-Qiangtang terranes.

In order to obtain the lithospheric structure of western Tibet, the lithospheric mantles of the accreted terranes are required to be gradually detached during the India-Asia collision and further replaced by the cold Indian lithosphere, with a process similar to that shown in Fig. 3. These geodynamic processes not only constrain the fate of the terranes' lithospheric mantle in western Tibet, but also account for the development of the plateau there. It is worth noting that the evolution of long-distance continental underthrusting in the numerical models (Fig. 3) indicates a similar dynamic process of Indian underthrusting beneath the Pamir-West Tibet as demonstrated in previous studies ${ }^{5,10,11}$. The Moho discontinuity lies at depths of about $60-70 \mathrm{~km}$ in this area ${ }^{5}$, which is also consistent with the "complete terrane detachment" mode (Fig. 3e). In addition, the numerical models suggest that the crustal thickening is driven by the combined effects of previous crustal shortening of the accreted terranes and subsequent underthrusting and duplexing of the Indian lower crust (Fig. 3).

In the model with complete terrane detachment (Fig. 3), the underthrusted cold Indian lithosphere beneath the collision zone may lead to relatively low thermal condition of the orogen, thus inhibiting large-scale magmatism. This agrees with magmatism in the western Tibetan plateau where the distribution of postcollisional volcanic rocks is limited. The main magmatic episode there is in the early Miocene ${ }^{43}$, which is supposed to be induced by the detachment of accreted terranes prior to the underthrusting of Indian lithosphere beneath the collision zone ${ }^{10}$, thus consistent with our model predictions (Fig. 3c, d).

In central-eastern Tibet (roughly east of $82^{\circ} \mathrm{E}$ ), the Indian lithosphere underthrusts the plateau probably to the Bangong-Nujiang suture or more southern ${ }^{5,6}$, where the Indian plate steeply subducts to the asthenosphere (Fig. 6b). In addition, the underthrusting of the North China plate beneath northeastern Tibet $^{40}$, together with the northward subduction of the Indian plate, jointly forms a complex lithospheric structure beneath the broad plateau similar to the "partial terrane detachment" mode 

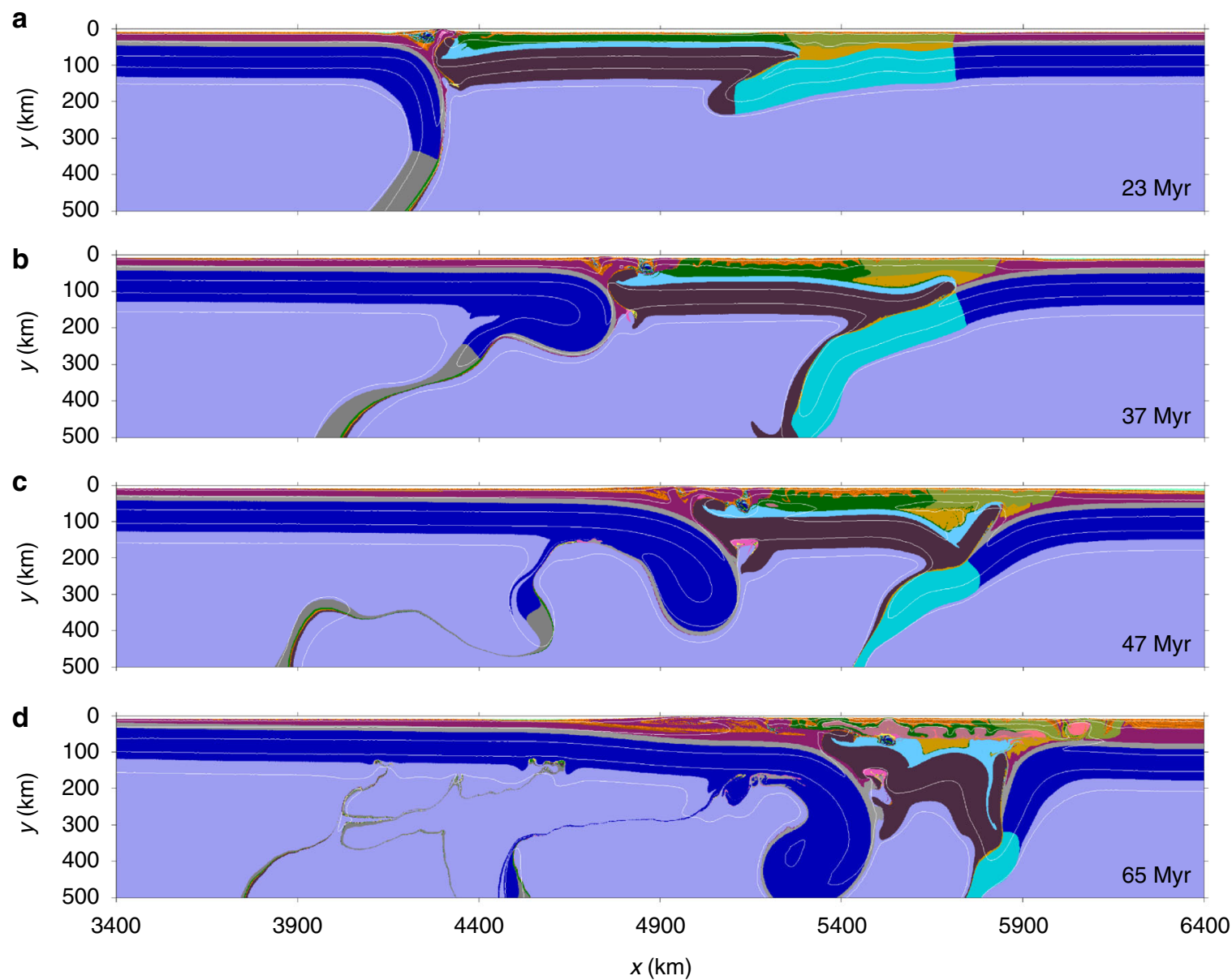

Fig. 4 Evolution of partial terrane detachment mode (Mode-II). The widths of the strong and weak terranes are 1200 and $700 \mathrm{~km}$, respectively. The reference density of the lithospheric mantle of both the strong and weak terranes is the same as the asthenosphere. Time of convergence is shown in each panel. Colors of rock types are as in Fig. 2a. White numbered lines are isotherms plotted every $300^{\circ} \mathrm{C}$ starting from $100^{\circ} \mathrm{C}$

(cf. Figs. 4d, 6b). The proceeding lithospheric thinning in northern Tibet, that is, the zone of poor Sn propagation ${ }^{5,12-14}$ denoted by the purple dashed line in Fig. 1, is presumably due to the upwelling of the partially molten materials from the subducting Indian slab (Fig. 4). On the other hand, the southward subduction of the Qaidam basin is still a widely debated issue (Fig. 6b). Previous receiver function images revealed the subduction of the Qaidam basin beneath northern Tibet from 100 $\mathrm{km}$ depth at the Kunlun fault to about $200 \mathrm{~km}$ depth in the Qiangtang terrane $e^{5,44,45}$, which appears to be supported by crustal shortening and northeastern propagation of thrust fault systems in northeastern Tibet ${ }^{19,46,47}$. However, this assumed subduction was not observed in a latest tomographic model based on a 3D adjoint tomography method ${ }^{48}$. Lithospheric deformation of the central-eastern Tibetan plateau is nevertheless primarily attributed to the subduction of Indian and Asian plates. The "partial terrane detachment" mode is thus well constrained by this firstorder lithospheric structure, while the absence of Qaidam basin in this study is due to the model simplifications.

The orogenic process illustrated in our models (Fig. 4) can be further supported by the spatial-temporal distribution of postcollisional magmatism in the broad central-eastern Tibet (Fig. 1), where four main magmatic episodes ${ }^{49}$ can be recognized from the early Eocene to the Quaternary. Firstly, widespread potassiumrich lavas erupted in the Qiangtang terrane from the Eocene to Oligocene $\mathrm{S}^{50}$. Then the magmatism migrated southwards, with adakitic and ultrapotassic lavas from late Oligocene to midMiocene in the Lhasa terrane ${ }^{51}$, accompanying the Miocene
Himalayan leucogranites derived from the melting of Indian crust $^{52}$. In the final episode, extensive potassic volcanism resumed since the mid-Miocene in the northern plateau ${ }^{53}$. Based on the numerical models (Fig. 4), the first magmatic episode was related to the subduction and further detachment of the weak terrane beneath the Qiangtang terrane as a consequence of the far-field India-Asia convergence. The second episode with adakitic and ultrapotassic characteristics may be attributed to the Indian subduction beneath the Lhasa terrane. Eventually, asthenospheric upwelling beneath the residue terranes not only caused obvious lithospheric thinning in the central Tibet, but also triggered extensive magmatism there since the Mid-Miocene (Fig. 4d).

Notably, there are two positive anomalies beneath the Indian-Tibetan plateau area in the tomographic images at 1016 $\mathrm{km}$ depth, which are denoted as TH and AS in Fig. 7. According to our numerical models, the elongated "TH" anomaly can be regarded as the remnant Neo-Tethyan oceanic slab ${ }^{54,55}$, which was detached from the Indian plate shortly after the collision and is now locating dramatically south of the Indus-Tsangpo suture. In contrast, the AS anomaly can be interpreted as the signature of the detached lithospheric mantle of the accreted terranes ${ }^{55}$. These interpretations are consistent with previous geophysical observations $^{55}$ and post-collisional volcanism ${ }^{49}$.

To conclude, the geodynamic evolution of the Himalayan-Tibetan orogen could be the combined processes of complete terrane detachment mode in western Tibet and partial terrane detachment mode in central-eastern Tibet, which are strongly controlled by the width and properties of the relatively 
a

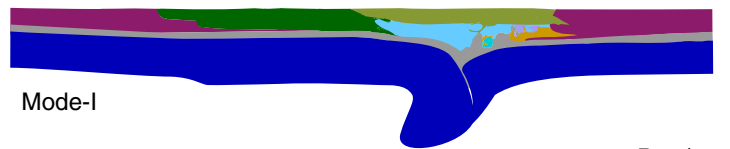

b

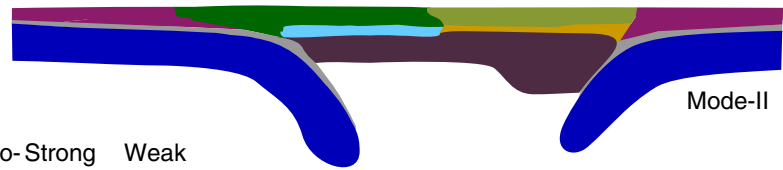

plate terrane terrane

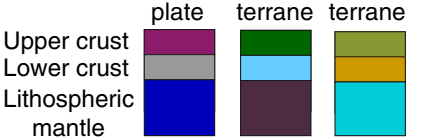

C

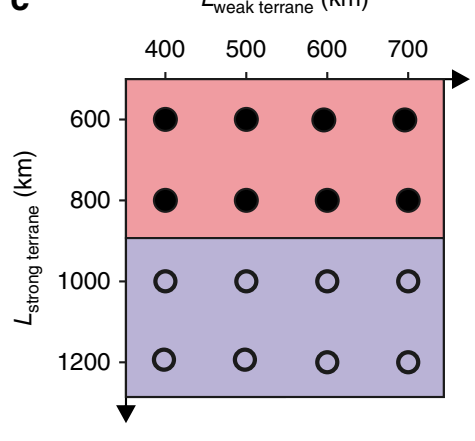

$$
\left(\Delta \rho_{\text {mantle }}=0 \mathrm{~kg} / \mathrm{m}^{3}\right)
$$

Mode-I: "Complete terrane detachment" d

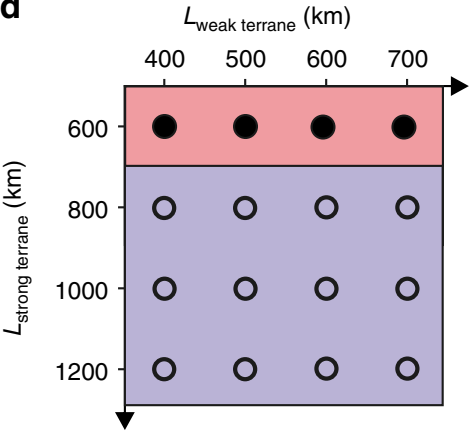

$\left(\Delta \rho_{\text {mantle }}=-10 \mathrm{~kg} / \mathrm{m}^{3}\right)$ e

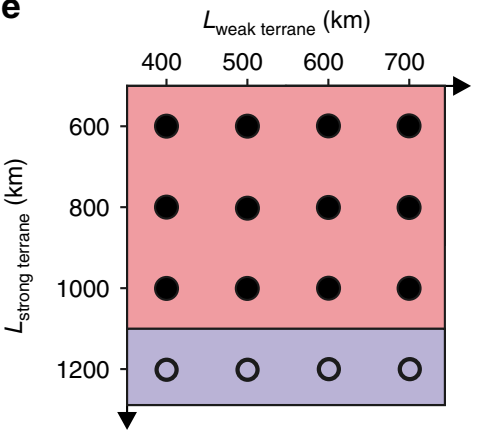

$\left(\Delta \rho_{\text {mantle }}=+10 \mathrm{~kg} / \mathrm{m}^{3}\right)$

Fig. 5 Phase diagram of the contrasting detachment modes. a Mode-l of complete terrane detachment, in which the lithospheric mantles of both the strong and weak terranes are detached during collision. b Mode-II of partial terrane detachment, in which only the weak terrane is detached, whereas the strong terrane is strongly deformed but not detached. c Regime diagram with the same reference density (i.e., at the same pressure and temperature) of the terrane lithospheric mantle and the asthenosphere. $\mathbf{d}$ Regime diagram with the reference density of lithospheric mantle of both terranes decreased to be $-10 \mathrm{~kg} \mathrm{~m}^{-3}$ lower than the asthenosphere. e Regime diagram with the reference density of lithospheric mantle of both terranes increased to be $+10 \mathrm{~kg} \mathrm{~m}^{-3}$ higher than the asthenosphere

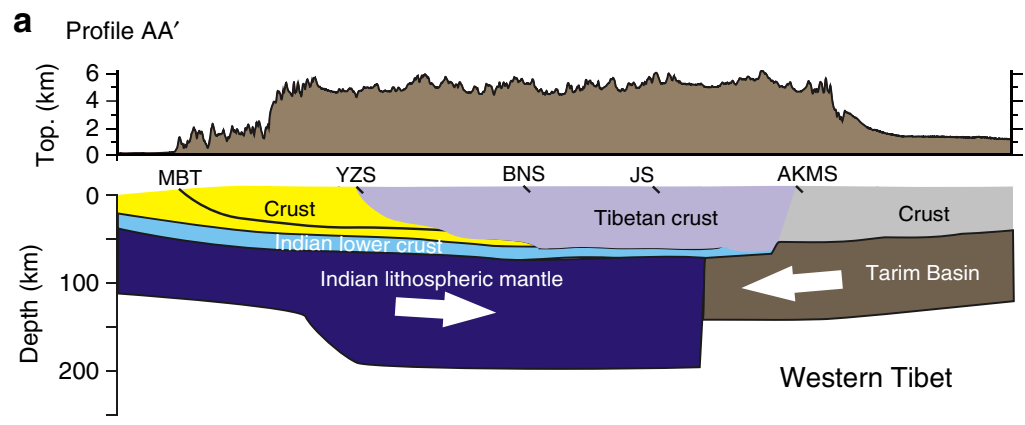

b Profile BB'

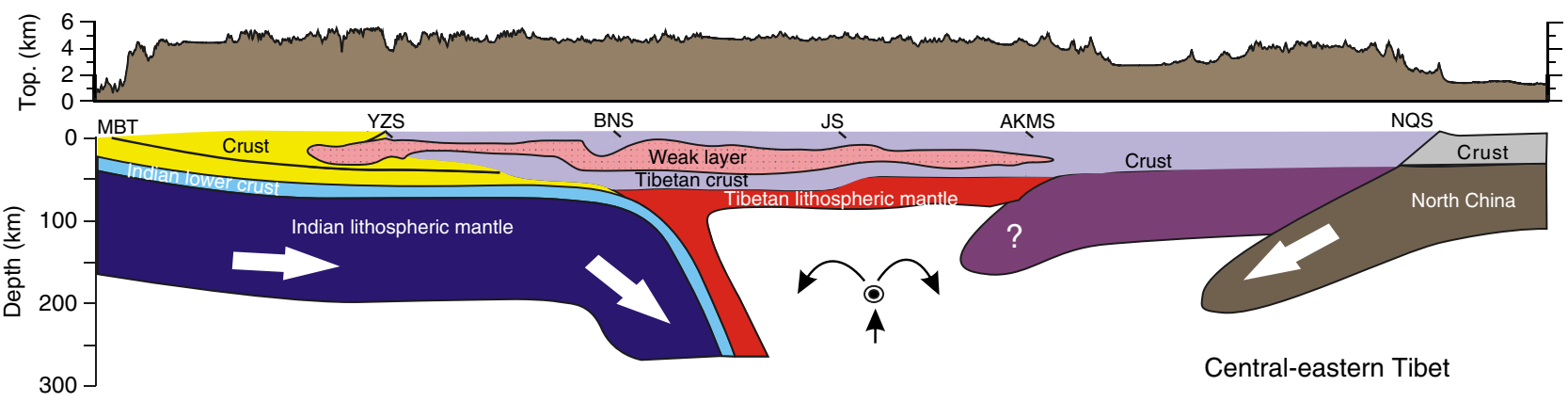

Fig. 6 Cross-section showing lithospheric structures of the Tibetan plateau. a The integrated schematic cross-section in western Tibet. The lithospheric structure is derived from the seismic data ${ }^{5,6}$; the crustal tectonic structure is from Searle et al. ${ }^{67}$ and Yin and Harrison ${ }^{3}$. b The integrated schematic crosssection in central-eastern Tibet, which is modified after Owens and Zandt ${ }^{13}$ and Ye et al. ${ }^{40}$. The weak layer in the middle crust is after Wang et al. ${ }^{68}$. The mantle flow underneath central and northern Tibet is supposed to be eastward ${ }^{69}$. The locations of both profiles are marked in Fig. 1 


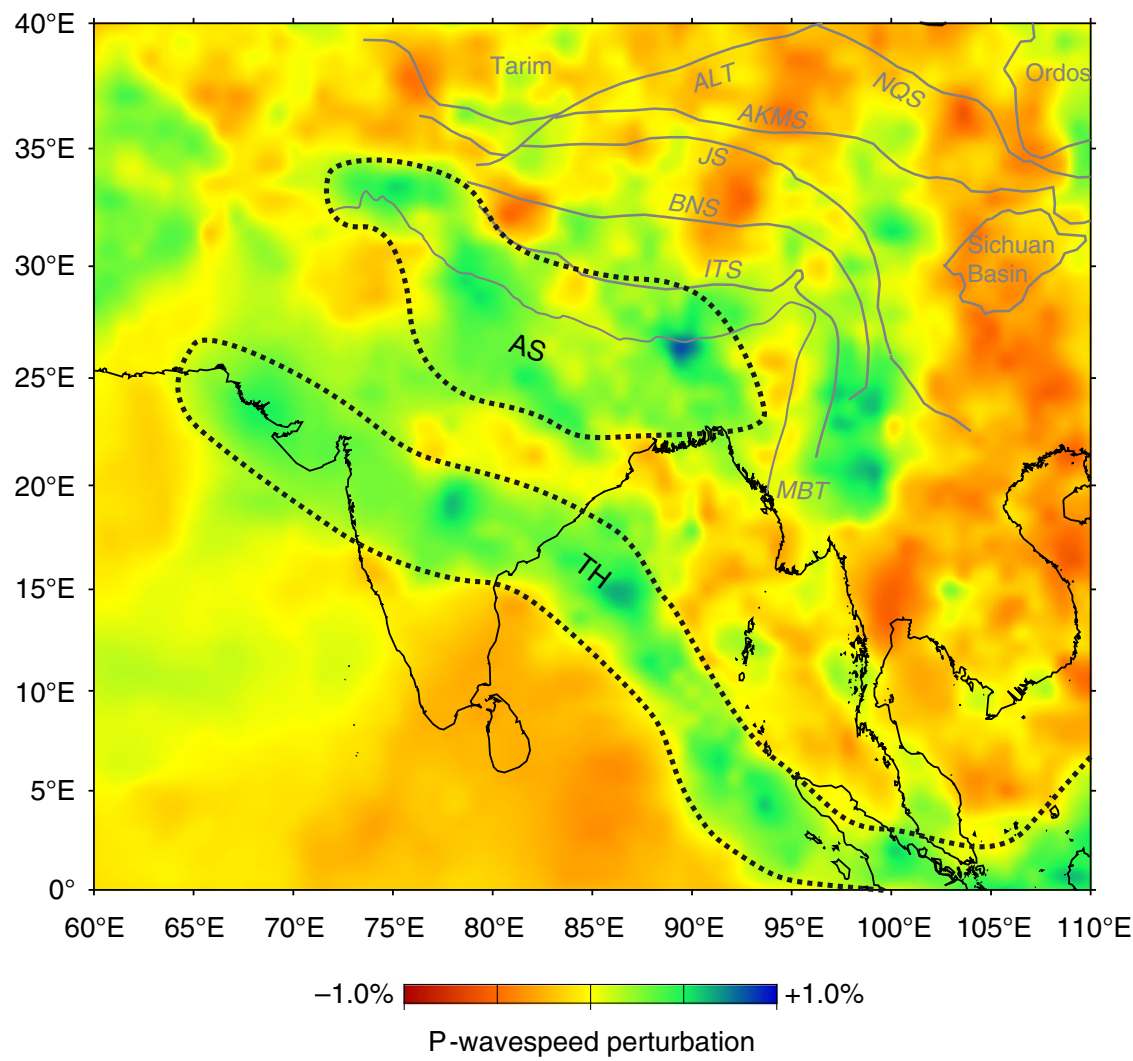

Fig. 7 Tomographic section at $1016 \mathrm{~km}$ depth suggesting two previous detachment events. Two high-speed anomalies, denoted as TH and AS, are observed. On the basis of their geometry and position, the TH anomaly is interpreted as the detached Neo-Tethyan oceanic slab ${ }^{54,55}$, whereas the AS anomaly might be the signature of the detached Tibetan lithospheric mantle during the India-Asia collision ${ }^{55}$. The Generic Mapping Tools ${ }^{66}$ was used to create the map, with the open source dataset of P-wave speed variations from $\mathrm{Li}$ et al. ${ }^{70}$.

strong Lhasa-Qiangtang terranes. The comparisons between the model results and geological/geophysical observations further suggest that the strong terranes might be originally narrower in western Tibet than in central-eastern Tibet at the onset of the India-Asia collision. It is reasonable, because (1) the present-day eastward-broadening shape of the Tibetan plateau probably inherited a similar geometric shape of the Lhasa-Qiangtang terranes in the incipient collision, and (2) the analyses of fold-andthrust belts indicate that the Cenozoic shortening of central-eastern Lhasa-Qiangtang terranes is generally larger than that of the western terranes 3,20 .

\section{Methods}

Numerical code and governing equations. The numerical experiments were performed using a finite-difference numerical code (I2VIS) with marker-in-cell technique ${ }^{56}$. The code solves the momentum, continuity, and heat conservation equations for a $2 \mathrm{D}$ creeping flow including thermal and chemical buoyant forces, that is,

2D stokes equations:

$$
\begin{gathered}
\frac{\partial \boldsymbol{\sigma}_{x x}^{\prime}}{\partial x}+\frac{\partial \boldsymbol{\sigma}_{x z}^{\prime}}{\partial z}=\frac{\partial P}{\partial x} \\
\frac{\partial \boldsymbol{\sigma}_{z x}^{\prime}}{\partial x}+\frac{\partial \boldsymbol{\sigma}_{z z}^{\prime}}{\partial z}=\frac{\partial P}{\partial z}-g \rho(C, M, P, T),
\end{gathered}
$$

where $x$ and $z$ are, respectively, horizontal and vertical coordinates, $g$ is gravitational acceleration, $\boldsymbol{\sigma}_{i j}^{\prime}$ are components of deviatoric stress tensor, and the density $\rho$ depends on composition $(C)$, melt fraction $(M)$, temperature $(T)$, and pressure $(P)$.

Incompressible continuity equation:

$$
\frac{\partial \mathbf{v}_{x}}{\partial x}+\frac{\partial \mathbf{v}_{z}}{\partial z}=0
$$

where $\mathbf{v}_{x}$ and $\mathbf{v}_{z}$ are velocity components.
Heat conservation equations:

$$
\begin{gathered}
\rho C_{\mathrm{p}}\left(\frac{\mathrm{DT}}{\mathrm{Dt}}\right)=-\frac{\partial \mathbf{q}_{x}}{\partial x}-\frac{\partial \mathbf{q}_{z}}{\partial z}+H_{\mathrm{r}}+H_{\mathrm{a}}+H_{\mathrm{s}}, \\
\mathbf{q}_{x}=-k(T, P, C) \frac{\partial T}{\partial x} \quad \mathbf{q}_{z}=-k(T, P, C) \frac{\partial T}{\partial z}, \\
H_{\mathrm{a}}=T \alpha \frac{\mathrm{d} P}{\mathrm{~d} t} \quad H_{\mathrm{s}}=\boldsymbol{\sigma}_{x x}^{\prime} \dot{\varepsilon}_{x x}+\boldsymbol{\sigma}_{z z}^{\prime} \dot{\varepsilon}_{z z}+2 \boldsymbol{\sigma}_{x z}^{\prime} \dot{x}_{x z},
\end{gathered}
$$

where $C_{\mathrm{p}}$ is the effective isobaric heat capacity, $\mathrm{DT} / \mathrm{D} t$ is the substantive time derivative of temperature, $\mathbf{q}_{x}$ and $\mathbf{q}_{z}$ are heat flux components, $H_{\mathrm{r}}, H_{\mathrm{a}}$, and $H_{\mathrm{s}}$ denote radioactive heat production, the energetic effect of isothermal (de) compression (i.e., adiabatic heating/cooling), and shear heating, respectively, $k(T, P$, $C)$ is the thermal conductivity as a function of temperature, pressure, and composition $^{57}, \alpha$ is thermal expansion coefficient, and $\dot{\varepsilon}_{i j}$ is the strain rate tensor.

Rheological model. The relationship between the deviatoric stress $\left(\boldsymbol{\sigma}_{i j}^{\prime}\right)$ and the strain rate $\left(\dot{\varepsilon}_{i j}\right)$ tensors is described by realistic visco-plastic constitutive laws. In case of incompressible viscous deformation, the viscous law of friction is:

$$
\begin{array}{ll}
\boldsymbol{\sigma}_{x x}^{\prime}=2 \eta_{\mathrm{eff}} \dot{\varepsilon}_{x x}, & \dot{\varepsilon}_{x x}=\frac{\partial \mathbf{v}_{x}}{\partial x}, \\
\sigma_{x z}^{\prime}=2 \eta_{\mathrm{eff}} \dot{\varepsilon}_{x z}, & \dot{\varepsilon}_{x z}=\frac{1}{2}\left(\frac{\partial \mathbf{v}_{x}}{\partial z}+\frac{\partial \mathbf{v}_{z}}{\partial x}\right), \\
\boldsymbol{\sigma}_{z z}^{\prime}=2 \eta_{\mathrm{eff}} \dot{\varepsilon}_{z z}, & \dot{\varepsilon}_{z z}=\frac{\partial \mathbf{v}_{z}}{\partial z},
\end{array}
$$

where $\eta_{\text {eff }}$ is the effective viscosity which depends on pressure, temperature, composition, strain rate, and degree of melting.

For rocks containing small melt fractions $(M<0.1, M$ is the volumetric melt fraction), the effective viscosity for ductile creep ( $\left.\eta_{\text {ductile }}\right)$ as a function of pressure, temperature, composition, and strain rate invariant is defined by:

$$
\eta_{\text {ductile }}=\left(\dot{\varepsilon}_{\mathrm{II}}\right)^{\frac{1-n}{n}}\left(A_{\mathrm{D}}\right)^{-\frac{1}{n}} \exp \left(\frac{E+P V}{n R T}\right),
$$

where $\dot{\varepsilon}_{\mathrm{II}}=\left(0.5 \dot{\varepsilon}_{i j} \dot{\varepsilon}_{i j}\right)^{1 / 2}$ is the second invariant of the strain rate tensor, and $n$, $A_{\mathrm{D}}, E$, and $V$ are experimentally determined flow law parameters (Supplementary Table 1), which represent stress exponent, material constant, activation energy, and activation volume, respectively. For rocks containing large melt fractions $(M \geq 0.1$, 
$M$ is the volumetric melt fraction), the effective viscosity of partial molten rocks is assigned to a low value of $10^{18} \mathrm{~Pa} \mathrm{~s}$, that is, the minimum cut-off value of the effective viscosity.

The ductile rheology is combined with a brittle/plastic rheology to yield an effective visco-plastic rheology. For this purpose, the extended Drucker-Prager yield criterion ${ }^{58}$ is implemented as follows:

$$
\begin{gathered}
\sigma_{\text {yield }}=C_{0}+P \sin \left(\varphi_{\text {eff }}\right), \\
\sin \left(\varphi_{\text {eff }}\right)=\sin (\varphi)(1-\lambda), \\
\eta_{\text {plastic }}=\frac{\sigma_{\text {yeld }}}{2 \dot{\varepsilon}_{\text {II }}},
\end{gathered}
$$

where $\sigma_{\text {yield }}$ is the yield stress, $C_{0}$ is the cohesion, $\varphi$ is the internal frictional angle, $P$ is the dynamic pressure, $\varphi_{\text {eff }}$ can be illustrated as the effective internal frictional angle that integrates the effects of the initial frictional angle $(\varphi)$ and pore fluid coefficient $(\lambda)^{59}$, and $\dot{\varepsilon}_{\mathrm{II}}$ is the second invariant of the strain rate tensor. In this paper, the plastic rheology is implemented by variable values of $\sin \left(\varphi_{\text {eff }}\right)$ for different rock types (Supplementary Table 2).

With the $\eta_{\text {ductile }}$ and $\eta_{\text {plastic }}$, visco-plastic rheology is assigned to the model by means of a Christmas tree-like criterion, where the rheological behavior depends on the minimum viscosity attained between the ductile and brittle/plastic fields ${ }^{58}$, which is further controlled by the cut-off values of $\left(10^{18}-10^{25} \mathrm{~Pa} \mathrm{~s}\right)$ :

$$
\eta_{\text {creep }}=\min \left(\eta_{\text {ductile }}, \eta_{\text {plastic }}\right) \text {. }
$$

Partial melting. The numerical code accounts for partial melting of the various lithologies using experimentally obtained $P-T$ dependent wet solidus and dry liquidus curves. Volumetric melt fraction $M$ is assumed to increase linearly with temperature according to the following relations ${ }^{60}$ :

$$
\begin{gathered}
M=0, \quad \text { when } T \leq T_{\text {solidus }}, \\
M=\frac{\left(T-T_{\text {solidus }}\right)}{\left(T_{\text {liquidus }}-T_{\text {soldus }}\right)}, \quad \text { when } T_{\text {solidus }}<T<T_{\text {liquidus }}, \\
M=1, \quad \text { when } T \geq T_{\text {liquidus }},
\end{gathered}
$$

where $T_{\text {solidus }}$ and $T_{\text {liquidus }}$ are the wet solidus and dry liquidus temperature of the given lithology (Supplementary Table 2), respectively.

Consequently, the effective density ( $\left.\rho_{\text {eff }}\right)$ of partially molten rocks varies with the amount of melt fraction and $P-T$ conditions according to the relation:

$$
\rho_{\text {eff }}=\rho_{\text {solid }}-M\left(\rho_{\text {solid }}-\rho_{\text {molten }}\right),
$$

where $\rho_{\text {solid }}$ and $\rho_{\text {molten }}$ are the densities of the solid and molten rock, respectively, which change with pressure and temperature according to the relation:

$$
\rho_{P, T}=\rho_{0}\left[1-\alpha\left(T-T_{0}\right)\right]\left[1+\beta\left(P-P_{0}\right)\right],
$$

where $\rho_{0}$ is the standard density at $P_{0}=0.1 \mathrm{MPa}$ and $T_{0}=298 \mathrm{~K}, \alpha$ is thermal expansion coefficient, and $\beta$ is compressibility coefficient.

The effects of latent heat $H_{\mathrm{L}}{ }^{61}$ are accounted for by an increased effective heat capacity $\left(C_{\mathrm{p}_{\text {eff }}}\right)$ and thermal expansion $\left(\alpha_{\text {eff }}\right)$ of the partially molten rocks $(0<M<$ $1)$, expressed as

$$
\begin{gathered}
C_{\mathrm{P}_{\text {eff }}}=C_{\mathrm{p}}+\mathrm{Q}_{\mathrm{L}}\left(\frac{\partial M}{\partial T}\right)_{P}, \\
\alpha_{\text {eff }}=\alpha+\rho \frac{\mathrm{Q}_{\mathrm{L}}}{T}\left(\frac{\partial M}{\partial P}\right)_{T},
\end{gathered}
$$

where $C_{\mathrm{p}}$ is the heat capacity of the solid crust and $Q_{\mathrm{L}}$ is the latent heat of melting of the crust.

Model configurations. The overall model setup is based on the tectonic structure of the Himalayan-Tibetan collision zone (Fig. 1), and represents the simplified lithospheric architecture including Neo-Tethyan subduction before the Cenozoic India-Asia collision. According to the stratigraphy and pre-Cenozoic structural configuration of the terranes constituting the Tibetan plateau, a strong terrane is embedded as the integration of the Lhasa and Qiangtang terranes, whereas the adjacent weak terrane represents the combined SPGZ, Kunlun-Qaidam, and Qilian terranes. All the continental plates and terranes consist of a 20-km-thick upper crust, a $15-\mathrm{km}$-thick lower crust, and an $85-\mathrm{km}$-thick lithospheric mantle. The oceanic lithosphere is $500-\mathrm{km}$ long and is composed of 8-km-thick crust and 72 $\mathrm{km}$-thick lithospheric mantle. The effects of the potentially thickened crust of the Lhasa terrane (here identified with variable thickness of the left part of the strong terrane; Supplementary Figs 1 and 2) prior to the India-Asia collision are also discussed in the Supplementary Note 2. Different compositions are shown in different colors (Fig. 2a).

Three different rheological profiles of continental lithosphere are designed (Fig. 2b), which represent pro-/retro-plate, strong terrane, and weak terrane, respectively. Flow laws of mafic granulite, plagioclase, and wet quartzite are separately applied for the lower crust of these three lithospheric profiles ${ }^{58}$. In addition, Quartzite and wet quartzite rheologies are used for the upper crust of continental plates and terranes, respectively, whereas the plagioclase rheology for the oceanic crust ${ }^{58}$. Both the lithospheric and asthenospheric mantle are represented by flow law of dry olivine ${ }^{62}$. The sensitivity of model results to the wetolivine-dominated asthenosphere (Supplementary Fig. 3) has also been discussed in the Supplementary Note 3. Detailed properties of different rock types are described in Supplementary Tables 1, 2.

The model domain has free-slip top boundary and side walls, whereas the lower boundary is treated as mass-conservative permeable to satisfy the free slip of an external boundary at $1000 \mathrm{~km}$ below the base of the model. External free slip condition conforms to global conservation of mass in the computational domain, and is implemented by using the following limitation for velocity components at the lower boundary: $\partial \mathbf{v}_{x} / \partial z=0, \partial \mathbf{v}_{z} / \partial z=-\mathbf{v}_{z} / \Delta z_{\text {external, }}$, where $\Delta z_{\text {external }}$ is the vertical distance from the lower boundary to the external boundary, where free slip $\left(\partial \mathbf{v}_{x} / \partial z=0, \mathbf{v}_{z}=0\right)$ is satisfied. Continental convergence is driven by a constant velocity of $5 \mathrm{~cm} \mathrm{yr}^{-1}$ assigned in the pro-plate. In order to evaluate the effects of a time-dependent, higher convergence velocity on the terrane deformation behaviors, we also constructed two additional groups of models and discussed the model results (Supplementary Figs. 4 and 5) in the Supplementary Note 4. Generally, a time-dependent, higher convergence velocity probably affects the magnitudes and rates of strain, but would not change the general detachment behaviors of terrane lithospheric mantle during convergence, as well as the resulted overall lithospheric structure.

The initial thermal structure of the continental plate is approximated by two linear interpolations, firstly from the surface $\left(0^{\circ} \mathrm{C}\right)$ to the Moho and then from the Moho to the base of the continental lithosphere $\left(1327^{\circ} \mathrm{C}\right)$. The initial Moho temperature of the two terranes is slightly higher $\left(+50^{\circ} \mathrm{C}\right)$ than that of the pro-plate and retro-plate. The latter are considered as typical stable cratons with a Moho temperature of $400{ }^{\circ} \mathrm{C}^{63}$. This makes sense when considering that (1) all these accreted terranes experienced repeated rifting events, oceanic subduction, and continent/arc-continent collision before the Cenozoic Indian collision with $\mathrm{Asia}^{3}$, and (2) both the Indian and Tarim-North China lithospheres separated from or amalgamated with other plates acting as stable, strong cratons during the Phanerozoic ${ }^{64}$. The initial thermal structure of the oceanic lithosphere is applied with $0^{\circ} \mathrm{C}$ on the surface and $1327^{\circ} \mathrm{C}$ at the bottom ${ }^{63}$.

Model limitations. In the numerical models, the general structures and evolution histories of the India-Asia collision and Tibetan plateau formation agree well with the natural observations. However, some detailed deformation characteristics are not fully resolved, for example, the exact position and activation time of the observed thrust faults, the exact width of the terranes in the plateau, the depth of the underthrusting slabs, and so on. These flaws are secondary and mainly due to the simplifications of the models, for example, the still simplified multi-terrane structure, the neglected erosional variability, and the time-dependent, differential convergence rates. In addition, these $2 \mathrm{D}$ numerical models do not involve the out-ofplane deformation (e.g., lateral extrusion, strike-slip faulting, toroidal mantle flow). In the aspect of resulted Himalayan width, we have tried to adjust the detailed parameters in order for the final agreement with nature (see Supplementary Note 5 and Supplementary Fig. 6). It is worth noting that the perfectly consistent model results with observations are not expected in this study, which focuses on the general evolution and controlling factors of the along-strike lithospheric structure of the Tibetan plateau.

Code availability. The numerical modeling code that supports the finding of this study is available from the corresponding author upon reasonable request.

\section{Data availability}

All the relevant data and model output presented in this study are available from the corresponding author upon reasonable request.

Received: 7 September 2017 Accepted: 22 August 2018 Published online: 17 September 2018

\section{References}

1. Williams, H. \& Hatcher, R. D. Suspect terranes and accretionary history of the Appalachian orogen. Geology 10, 530-536 (1982).

2. Rosenbaum, G. \& Lister, G. S. The Western Alps from the Jurassic to Oligocene: spatio-temporal constraints and evolutionary reconstructions. Earth Sci. Rev. 69, 281-306 (2005).

3. Yin, A. \& Harrison, T. M. Geologic evolution of the Himalayan-Tibetan orogen. Annu. Rev. Earth Planet. Sci. 28, 211-280 (2000).

4. Whitmeyer, S. J. \& Karlstrom, K. E. Tectonic model for the Proterozoic growth of North America. Geosphere 3, 220-259 (2007).

5. Zhao, J. et al. The boundary between the Indian and Asian tectonic plates below Tibet. Proc. Natl. Acad. Sci. USA 107, 11229-11233 (2010). 
6. Li, C., Van der Hilst, R. D., Meltzer, A. S. \& Engdahl, E. R. Subduction of the Indian lithosphere beneath the Tibetan Plateau and Burma. Earth Planet. Sci. Lett. 274, 157-168 (2008).

7. Nunn, C., Roecker, S. W., Priestley, K. F., Liang, X. \& Gilligan, A. Joint inversion of surface waves and teleseismic body waves across the Tibetan collision zone: the fate of subducted Indian lithosphere. Geophys. J. Int. 198, 1526-1542 (2014).

8. Chen, Y., Li, W., Yuan, X., Badal, J. \& Teng, J. Tearing of the Indian lithospheric slab beneath southern Tibet revealed by SKS-wave splitting measurements. Earth Planet. Sci. Lett. 413, 13-24 (2015).

9. Kumar, P., Yuan, X., Kind, R. \& Kosarev, G. The lithosphere-asthenosphere boundary in the Tien Shan-Karakoram region from $S$ receiver functions: evidence for continental subduction. Geophys. Res. Lett. 32, L07305 (2005).

10. Rutte, D. et al. Building the Pamir-Tibetan Plateau-Crustal stacking, extensional collapse, and lateral extrusion in the Central Pamir: 2. Timing and rates. Tectonics 36, 385-419 (2017).

11. Schneider, F. M. et al. Seismic imaging of subducting continental lower crust beneath the Pamir. Earth Planet. Sci. Lett. 375, 101-112 (2013).

12. Barazangi, M. \& Ni, J. Velocities and propagation characteristics of Pn and Sn beneath the Himalayan arc and Tibetan plateau: possible evidence for underthrusting of Indian continental lithosphere beneath Tibet. Geology 10, 179-185 (1982).

13. Owens, T. J. \& Zandt, G. Implications of crustal property variations for models of Tibetan plateau evolution. Nature 387, 37-43 (1997).

14. McNamara, D., Walter, W., Owens, T. \& Ammon, C. Upper mantle velocity structure beneath the Tibetan Plateau from Pn travel time tomography. J. Geophys. Res. 102, 493-505 (1997).

15. Chen, L., Capitanio, F. A., Liu, L. \& Gerya, T. V. Crustal rheology controls on the Tibetan plateau formation during India-Asia convergence. Nat. Commun. 8, 15992 (2017).

16. Zhu, D.-C. et al. The origin and pre-Cenozoic evolution of the Tibetan Plateau. Gondwana Res. 23, 1429-1454 (2013).

17. Gehrels, G. et al. Detrital zircon geochronology of pre-Tertiary strata in the Tibetan-Himalayan orogen. Tectonics 30, TC5016 (2011)

18. Wu, C. et al. Pre-Cenozoic geologic history of the central and northern Tibetan Plateau and the role of Wilson cycles in constructing the Tethyan orogenic system. Lithosphere 8, 254-292 (2016).

19. Tapponnier, P. et al. Oblique stepwise rise and growth of the Tibet Plateau. Science 294, 1671-1677 (2001).

20. Li, Y. et al. Propagation of the deformation and growth of the Tibetan-Himalayan orogen: a review. Earth Sci. Rev. 143, 36-61 (2015).

21. Ding, L., Kapp, P., Zhong, D. L. \& Deng, W. M. Cenozoic volcanism in Tibet: evidence for a transition from oceanic to continental subduction. J. Petrol. 44, 1833-1865 (2003).

22. Ding, L., Kapp, P., Yue, Y. \& Lai, Q. Postcollisional calc-alkaline lavas and xenoliths from the southern Qiangtang terrane, central Tibet. Earth Planet. Sci. Lett. 254, 28-38 (2007).

23. England, P. \& Houseman, G. Finite strain calculations of continental deformation 2. Comparison with the India-Asia collision Zone. J. Geophys. Res. 91, 3664-3676 (1986).

24. Li, Z. H., Xu, Z. Q., Gerya, T. \& Burg, J. P. Collision of continental corner from 3-D numerical modeling. Earth Planet. Sci. Lett. 380, 98-111 (2013).

25. Kelly, S., Butler, J. P. \& Beaumont, C. Continental collision with a sandwiched accreted terrane: Insights into Himalayan-Tibetan lithospheric mantle tectonics? Earth Planet. Sci. Lett. 455, 176-195 (2016).

26. Royden, L. H. et al. Surface deformation and lower crustal flow in eastern Tibet. Science 276, 788-790 (1997).

27. Beaumont, C., Jamieson, R. A., Nguyen, M. H. \& Lee, B. Himalayan tectonics explained by extrusion of a low-viscosity crustal channel coupled to focused surface denudation. Nature 414, 738-742 (2001).

28. Vogt, K. \& Gerya, T. V. From oceanic plateaus to allochthonous terranes: numerical modelling. Gondwana Res. 25, 494-508 (2014).

29. Tetreault, J. L. \& Buiter, S. J. H. Geodynamic models of terrane accretion: testing the fate of island arcs, oceanic plateaus, and continental fragments in subduction zones. J. Geophys. Res. 117, B08403 (2012).

30. Moresi, L., Betts, P. G., Miller, M. S. \& Cayley, R. A. Dynamics of continental accretion. Nature 508, 245-248 (2014).

31. Li, Z.-H., Liu, M. \& Gerya, T. Lithosphere delamination in continental collisional orogens: a systematic numerical study. J. Geophys. Res. 121, 5186-5211 (2016).

32. Dewey, J. F., Shackleton, R. M., Chengfa, C. \& Yiyin, S. The tectonic evolution of the Tibetan Plateau. Philos. Trans. R. Soc. Lond. 327, 379-413 (1988).

33. Metcalfe, I. Gondwanaland dispersion, Asian accretion and evolution of eastern Tethys. Aust. J. Earth Sci. 43, 605-623 (1996).

34. Baxter, A. T., Aitchison, J. C. \& Zyabrev, S. V. Radiolarian age constraints on Mesotethyan ocean evolution, and their implications for development of the Bangong-Nujiang suture, Tibet. J. Geol. Soc. 166, 689-694 (2009).
35. Song, S., Niu, Y., Su, L., Zhang, C. \& Zhang, L. Continental orogenesis from ocean subduction, continent collision/subduction, to orogen collapse, and orogen recycling: the example of the North Qaidam UHPM belt, NW China. Earth Sci. Rev. 129, 59-84 (2014).

36. Zuza, A. V. et al. Tectonic evolution of the Qilian Shan: an early Paleozoic orogen reactivated in the Cenozoic. Geol. Soc. Am. Bull. 130, 881-925 (2017).

37. Yin, A., Manning, C. E., Lovera, O., Menold, C. A. \& Chen, X. H. Early paleozoic tectonic and thermomechanical evolution of ultrahigh-pressure (UHP) metamorphic rocks in the northern Tibetan plateau, northwest China. Int. Geol. Rev. 49, 681-716 (2007).

38. Yin, A., Dang, Y.-Q., Zhang, M., Chen, X.-H. \& McRivette, M. W. Cenozoic tectonic evolution of the Qaidam basin and its surrounding regions (Part 3): structural geology, sedimentation, and regional tectonic reconstruction. Geol. Soc. Am. Bull. 120, 847-876 (2008).

39. O’Reilly, S., Griffin, W., Poudjom Djomani, Y. \& Morgan, P. Are lithospheres forever? Tracking changes in subcontinental lithospheric mantle through time. GSA Today 11, 4-10 (2001).

40. Ye, Z. et al. Seismic evidence for the North China plate underthrusting beneath northeastern Tibet and its implications for plateau growth. Earth Planet. Sci. Lett. 426, 109-117 (2015).

41. Kind, R. \& Yuan, X. Seismic images of the biggest crash on Earth. Science 329, 1479-1480 (2010).

42. Guo, X. Y. et al. Nonuniform subduction of the Indian crust beneath the Himalayas. Sci. Rep. 7, 12497 (2017).

43. Malz, N., Pfänder, J. A., Ratschbacher, L. \& Hacker, B. R. Cretaceous-Cenozoic magmatism in the Pamir and a comparison with Tibet. In: The 27th Himalaya-Karakoram-Tibet Workshop (HKT) 119 (Kathmandu, Nepal, 2012).

44. Kind, R. et al. Seismic images of crust and upper mantle beneath Tibet: evidence for Eurasian plate subduction. Science 298, 1219-1221 (2002).

45. Zhao, W. et al. Tibetan plate overriding the Asian plate in central and northern Tibet. Nat. Geosci. 4, 870-873 (2011).

46. Meyer, B. et al. Crustal thickening in Gansu-Qinghai, lithospheric mantle subduction, and oblique, strike-slip controlled growth of the Tibet plateau. Geophys. J. Int. 135, 1-47 (1998).

47. Wang, C. et al. A mid-crustal strain-transfer model for continental deformation: a new perspective from high-resolution deep seismic-reflection profiling across NE Tibet. Earth Planet. Sci. Lett. 306, 279-288 (2011).

48. Chen, M. et al. Lithospheric foundering and underthrusting imaged beneath Tibet. Nat. Commun. 8, 15659 (2017).

49. Chung, S.-L. et al. Tibetan tectonic evolution inferred from spatial and temporal variations in post-collisional magmatism. Earth Sci. Rev. 68, 173-196 (2005).

50. Wang, Q. et al. Eocene melting of subducting continental crust and early uplifting of central Tibet: evidence from central-western Qiangtang high-K calc-alkaline andesites, dacites and rhyolites. Earth Planet. Sci. Lett. 272, 158-171 (2008).

51. Nomade, S., Renne, P. R., Mo, X. X., Zhao, Z. D. \& Zhou, S. Miocene volcanism in the Lhasa block, Tibet: spatial trends and geodynamic implications. Earth Planet. Sci. Lett. 221, 227-243 (2004).

52. Guo, Z. \& Wilson, M. The Himalayan leucogranites: Constraints on the nature of their crustal source region and geodynamic setting. Gondwana Res. 22, 360-376 (2012).

53. Guo, Z. F., Wilson, M., Liu, J. Q. \& Mao, Q. Post-collisional, potassic and ultrapotassic magmatism of the northern Tibetan Plateau: Constraints on characteristics of the mantle source, geodynamic setting and uplift mechanisms. J. Petrol. 47, 1177-1220 (2006).

54. Van der Voo, R., Spakman, W. \& Bijwaard, H. Tethyan subducted slabs under India. Earth Planet. Sci. Lett. 171, 7-20 (1999).

55. Replumaz, A., Guillot, S., Villaseñor, A. \& Negredo, A. M. Amount of Asian lithospheric mantle subducted during the India/Asia collision. Gondwana Res. 24, 936-945 (2013).

56. Gerya, T. V. \& Yuen, D. A. Characteristics-based marker-in-cell method with conservative finite-differences schemes for modeling geological flows with strongly variable transport properties. Phys. Earth Planet. Inter. 140, 293-318 (2003).

57. Hofmeister, A. M. Mantle values of thermal conductivity and the geotherm from phonon lifetimes. Science 283, 1699-1706 (1999).

58. Ranalli, G. Rheology of the Earth 2nd edn (Chapman \& Hall, New York, 1995).

59. Brace, W. F. \& Kohlstedt, D. L. Limits on lithospheric stress imposed by laboratory experiments. J. Geophys. Res. 85, 6248-6252 (1980).

60. Burg, J. P. \& Gerya, T. The role of viscous heating in Barrovian metamorphism of collisional orogens: thermomechanical models and application to the Lepontine Dome in the Central Alps. J. Metamorph. Geol. 23, 75-95 (2005). 
61. Stuwe, K. Thermal buffering effects at the solidus: implications for the equilibration of partially melted metamorphic rocks. Tectonophysics $\mathbf{2 4 8}$, 39-51 (1995)

62. Burov, E. \& Watts, A. The long-term strength of continental lithosphere: "jelly sandwich" or "crème brûlée"? GSA Today 16, 4-10 (2006).

63. Turcotte, D. L. \& Schubert, G. Geodynamics 2nd edn (Cambridge Univ. Press, Cambridge, 2002).

64. Şengör, A. M. C. Continental interiors and cratons: any relation? Tectonophysics 305, 1-42 (1999).

65. Schwab, M. et al. Assembly of the Pamirs: age and origin of magmatic belts from the southern Tien Shan to the southern Pamirs and their relation to Tibet. Tectonics 23, TC4002 (2004).

66. Wessel, P., Smith, W. H. F., Scharroo, R., Luis, J. \& Wobbe, F. Generic mapping tools: improved version released. EOS Trans. AGU 94, 409-410 (2013).

67. Searle, M. P., Elliott, J., Phillips, R. \& Chung, S.-L. Crustal-lithospheric structure and continental extrusion of Tibet. J. Geol. Soc. 168, 633-672 (2011).

68. Wang, Q. et al. Pliocene-Quaternary crustal melting in central and northern Tibet and insights into crustal flow. Nat. Commun. 7, 11888 (2016).

69. Tilmann, F. \& Ni, J. \& INDEPTH III Seismic Team. Seismic imaging of the downwelling Indian lithosphere beneath central Tibet. Science 300, 1424-1427 (2003).

70. Li, C., van der Hilst, R. D., Engdahl, E. R. \& Burdick, S. A new global model for P wave speed variations in Earth's mantle. Geochem. Geophys. Geosyst. 9, Q05018 (2008)

\section{Acknowledgements}

This research was supported by the Strategic Priority Research Program (B) of Chinese Academy of Sciences (XDB18000000), the NSFC projects $(41704091,41774108$, $41590865,41490613,41622404)$, the 973 Project of China (2015CB856106), the National Key Research and Development Project of China (2016YFC0600310), and the National "Qian-Ren" Program. The numerical modeling presented in this paper was carried out on the high-performance computing cluster (HPC) in the National Supercomputer Center in Guangzhou (NSCC-GZ). The Generic Mapping Tools ${ }^{66}$ and the software CorelDRAW were used to create Figs. 1, 7 .

\section{Author contributions}

P.H. performed the numerical experiments, interpreted results, and wrote the manuscript. Z.-H.L. designed the study, modified the code, and wrote the manuscript. T.G. provided the original code and discussed the model results. W.F., K.-J.Z., H.Z., and Y.S. contributed to the model interpretation and geological application.

\section{Additional information}

Supplementary Information accompanies this paper at https://doi.org/10.1038/s41467018-06233-x.

Competing interests: The authors declare no competing interests.

Reprints and permission information is available online at http://npg.nature.com/ reprintsandpermissions/

Publisher's note: Springer Nature remains neutral with regard to jurisdictional claims in published maps and institutional affiliations.

\section{(c) (i)}

Open Access This article is licensed under a Creative Commons Attribution 4.0 International License, which permits use, sharing, adaptation, distribution and reproduction in any medium or format, as long as you give appropriate credit to the original author(s) and the source, provide a link to the Creative Commons license, and indicate if changes were made. The images or other third party material in this article are included in the article's Creative Commons license, unless indicated otherwise in a credit line to the material. If material is not included in the article's Creative Commons license and your intended use is not permitted by statutory regulation or exceeds the permitted use, you will need to obtain permission directly from the copyright holder. To view a copy of this license, visit http://creativecommons.org/ licenses/by/4.0/.

(C) The Author(s) 2018 